\title{
Brasil: segunda grande transformação no trabalho?
}

\author{
MARCIO POCHMANN ${ }^{I}$
}

$\mathrm{D}$

O SEU surgimento na condição de colônia portuguesa, passando pela independência (1822) e pela república (1889), até chegar ao século XX, o Brasil conheceu somente uma grande transformação no trabalho. E não se pode atribuir ao fim do escravismo o protagonismo maior dessa transformação, tendo em vista que a prevalência da sociedade agrária terminou por submeter o liberto trabalho humano à exclusão dos direitos sociais e trabalhistas.

Entre as décadas de 1930 e 1970, com a transição da antiga sociedade agrária para a urbana e industrial, tornou-se possível o estabelecimento da base material pela qual pôde percorrer o processo de modernização do trabalho no país. Naquele período, a economia brasileira assumiu a posição de um dos mais dinâmicos crescimentos da produção no mundo, acompanhado por significativa transformação no trabalho, com avanços no acesso aos direitos sociais e trabalhistas jamais identificados no país.

Apesar disso, a ausência de maioria política capaz de levar a cabo as reformas clássicas do capitalismo contemporâneo, com a agrária, a tributária e a social, possibilitou que a trajetória pregressa da desigualdade social herdada da sociedade agrária se mantivesse, com elevada concentração da riqueza, renda e poder. Em 1980, o mesmo país que assumia o posto de oitava economia do mundo era considerado o terceiro mais desigual do planeta, tendo ainda quase a metade de sua população vivendo na pobreza, com a informalidade ultrapassando $50 \%$ dos ocupados e o rendimento do trabalho equivalendo à metade da renda nacional.

Nas duas últimas décadas do século XX, contudo, o Brasil passou a retroagir no tempo. Ao perseguir a marcha da regressão econômica e social evidenciada pelas políticas de ajuste exportador nos anos 1980 e do neoliberalismo na década de 1990, a economia nacional decaiu da oitava posição mundial para a décima terceira, passando da décima terceira para a terceira posição no ranking do desemprego global e comprimindo a parcela salarial de $50 \%$ para $39 \%$ da renda nacional.

Desde a primeira década do século XXI, o Brasil voltou a apontar para uma segunda grande transformação no trabalho. Pelo caminho da efetividade do regime democrático surgiu nova maioria política pós-neoliberal, capaz de combinar a retomada do crescimento econômico com avanços sociais fundamentais para o mundo do trabalho. 
Em razão disso a presente contribuição espera agregar conhecimento ao entendimento acerca do curso de uma possível transformação profunda do trabalho no Brasil. Três são as suas partes constitutivas, a começar pela análise das condições gerais da primeira transformação no trabalho no país entre as décadas de 1930 e 1970. Na sequência, apresenta-se o movimento recente que parece sinalizar para uma segunda grande transformação do trabalho no Brasil, bem como os desafios que se interpõem a ela.

\section{Uma primeira grande transformação do trabalho}

Pelo predomínio das características inerentes ao funcionamento das sociedades agrárias, o conjunto dos ganhos de produtividade era, em geral, contido, salvo em determinados ciclos de exportação dos produtos primários até pelo menos o início do século XX. Diante disso, as possibilidades de expansão da economia como um todo permaneciam minimizadas pela exclusividade do rendimento associado à exploração do setor primário (extrativismo mineral e agropecuária) e pela ínfima divisão do trabalho que consagrava as naturais vantagens comparativas.

O padrão de vida resultante era geralmente primitivo e limitado ao exercício do trabalho pela sobrevivência, fundamentalmente, com jornadas de até 15 horas diárias e início laboral desde os cinco anos de idade até praticamente a morte. A total ausência de regulação nas relações de trabalho era uma marca identificável com a presença dominante do Estado mínimo.

As funções principais do Estado se limitavam ao exercício do monopólio da moeda, da tributação e da violência. Ademais, com a prevalência da concorrência selvagem nos mercados, o trabalho se mantinha desvalorizado e incapaz de romper com a pobreza, mesmo com sua transição de formas anteriormente forçadas (servidão e escravidão) para as de subordinação da mão de obra livre.

Por ser uma economia primário-exportadora, o Brasil não detinha a autodeterminação do seu próprio progresso, dependendo da demanda e de preços dos produtos primários definidos externamente. Em conformidade com os fluxos comerciais e financeiros internacionais é que se estabeleciam os limites dos avanços pelos quais as antigas sociedades agrárias - como o Brasil - se reproduziam em torno de estruturas sociais primitivas e atrasadas, com apenas alguns pontos de modernidade capitalista.

Assim, o eixo estruturador da base material e social seguia sendo o agrário, mesmo com alguma presença localizada de indústrias dispersas, o que reforçava a própria condição do subdesenvolvimento expresso pela diversidade das realidades regionais. ${ }^{1}$

Nos países que se industrializaram a partir do século XVIII, como na Inglaterra, e posteriormente Alemanha, França, Estados Unidos, Itália, Rússia, o capitalismo deslocou-se da antiga sociedade agrária e potencializou enormemente a moderna sociedade urbana e industrial. Pelo processo da mecanização ocorreram significativos ganhos de produtividade ante a incorporação tecnológica e a consequente ampliação na divisão do trabalho. 
Da mesma forma, o estranhamento laboral gerado pela intensificação do trabalho urbano pelo ritmo acelerado da mecanização rapidamente se expressou pelas lutas e reivindicações voltadas à liberação de parte do tempo da vida comprometido com o trabalho pela sobrevivência. Assim, na passagem para o século XX, surgiram as primeiras iniciativas de regulação do mercado de trabalho, como a jornada laboral de oito horas diárias, descanso semanal, férias e ingresso no mercado de trabalho após os quatorze anos de idade e aposentadoria a partir de certo tempo de contribuição.

Para isso, contudo, a efetivação de reformas como a tributária, capaz de ampliar o fundo público para além dos limites estabelecidos pelo antigo Estado mínimo (liberal), se tornou fundamental. O novo Estado de Bem-Estar Social absorveu maior quantidade de empregados na administração pública, esvaziando a dependência da geração de postos de trabalho exclusivamente pelo setor privado.

Ao mesmo tempo foram criadas as condições fundamentais para a ampliação da inatividade de parcela da classe trabalhadora. Por meio da garantia de transferência da renda do fundo público para determinados segmentos da sociedade, como as crianças e adolescentes, os idosos, doentes e portadores de deficiências físicas e mentais, tornou-se possível a liberação da dependência extrema do mercado de trabalho para a vida.

Tudo isso, é claro, assumiu maior evidência no século XX, especialmente com os avanços econômicos possibilitados pela segunda revolução tecnológica e por acordos social-democratas em meio ao desastre da Grande Depressão capitalista advinda de 1929. Da mesma forma, a existência de alternativa à economia de mercado, constatado pelos êxitos da Revolução Russa de 1917, amorteceram resistências maiores de parte dos ricos e conservadores.

Nesse sentido, as duas grandes guerras mundiais (1914-1917 e 19391945) destacam-se por seus impactos, entre eles a emergência de nações como a Alemanha e os Estados Unidos a disputar a sucessão da antiga liderança inglesa global. Com o fim da década de 1940, um novo centro do mundo se estabeleceu sob a liderança dos Estados Unidos, cujo modo de vida, o american way of life, se generalizou mais rapidamente pelo consumo de bens e serviços do que pela descentralização da produção de manufatura pelo mundo.

Em plena guerra fria (1947-1991), mais de 150 países se constituíram ante o desmoronamento dos antigos impérios e de suas colônias predominantes. Assim, países passaram a ter condições de estabelecer políticas públicas de abrangência nacional, o que permitiu disseminar os sistemas nacionais de educação, trabalho, saúde, entre outros.

No Brasil primário exportador, somente o café representava mais de dois terços de toda a pauta de exportação. Com o abalo do sistema centro-periferia imposto pela Grande Depressão de 1929, as formas da integração comercial e financeira internacional foram colocadas em xeque, impossibilitando que a demanda externa continuasse a dinamizar economias nacionais como a brasileira. 
Naquele contexto de crise no centro do capitalismo da década de 1930 é que o Brasil construiu internamente uma nova maioria política de corte não liberal e que, mesmo heterogênea e pouco democrática, se mostrou suficiente para viabilizar a transição para a modernidade da sociedade urbana. Como resposta às oligarquias liberais agrárias da época houve a consolidação de instituições republicanas comprometidas com direitos civis, políticos e sociais.

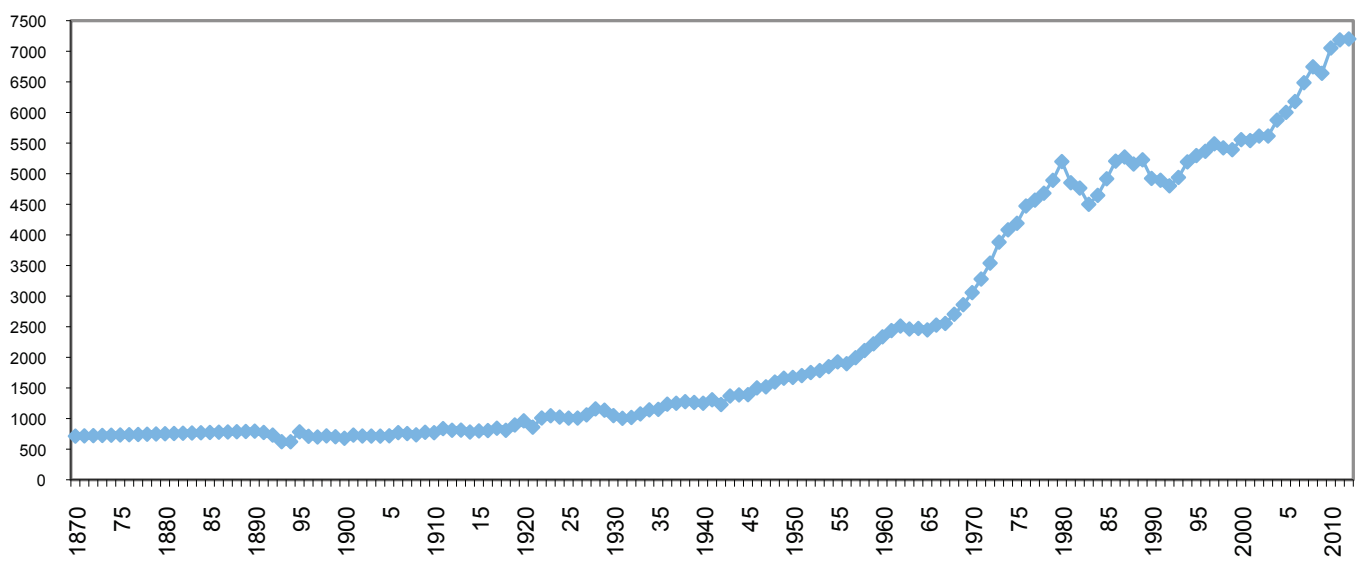

Fonte: Maddison (2008); IBGE/contas nacionais (elaboração própria).

Gráfico l - Brasil: evolução do Produto Interno Bruto per capita (em \%)

Assim, uma primeira grande transformação do trabalho ganhou importância no Brasil com o reposicionamento do Estado ampliado em defesas de políticas nacional-desenvolvimentistas. Por consequência da significativa expansão produtiva, o país conviveu com a urbanização e a estruturação do seu mercado nacional de trabalho em torno do emprego assalariado formal.

No período de 1930 a 1980, por exemplo, a renda per capita do brasileiro cresceu 3,3\% ao ano, em média, enquanto entre os anos 1880 e 1930 a renda por habitante havia aumentado somente $0,6 \%$ como média anual. Durante meio século da industrialização nacional, a renda do brasileiro cresceu 5,5 vezes mais do que nos cinquenta anos de predomínio da sociedade agrária precedente.

$\mathrm{Na}$ comparação com o mundo, registra-se que a renda per capita aumentou $1,8 \%$ em média ao ano, abaixo da expansão de $3,9 \%$ no Brasil no período de 1950 a 1980. Não obstante a concretização das condições necessárias para a expansão da classe trabalhadora assentada no emprego formal e nos direitos sociais e trabalhistas, o progresso econômico deu sinais inegáveis de ter se descolado dos contidos avanços sociais no Brasil. ${ }^{2}$

Por conta disso, a questão social manteve-se sem resolução compatível com os avanços econômicos brasileiros. A exclusão social permaneceu ativa, identificada que foi pelas dimensões decorrentes da elevada pobreza, marginalidade social, informalidade e precariedade no trabalho, entre outras formas de manifestação. 
No mesmo sentido, a urbanização da sociedade se deu com infraestrutura rudimentar para a maior parte da população, salvo verdadeiras ilhas de modernidades estabelecidas em algumas poucas áreas prósperas do país. Possivelmente, a ausência do regime democrático pleno, acompanhado de reformas civilizatórias do capitalismo como a agrária, tributária e social, fez do Brasil um dos espaços territoriais de piores indicadores da desigualdade da renda e atraso social. ${ }^{3}$ No ano 1980, por exemplo, o país se situava entre as oito mais importantes economias do mundo, embora mantivesse quase a metade de sua população na condição de pobreza e distante da construção do Estado de Bem-Estar Social.

O desemprego urbano, ainda que relativamente baixo, era acompanhado por enorme horda de trabalho informal, distante dos direitos sociais e trabalhistas. Para os empregados formais, a ausência da democratização nas relações de trabalho fazia prevalecer o arrocho salarial.

\section{Sinais de uma segunda grande transformação do trabalho}

Nas duas últimas décadas do século XX, a renda per capita nacional cresceu apenas $0,3 \%$ ao ano, ou seja, manteve-se praticamente semiestagnada, com ritmo de expansão abaixo da época da sociedade agrária no Brasil. A crise da dívida externa logo no início dos anos 1980 terminou por abalar a trajetória do projeto urbano e industrial, impondo a adoção dos programas de ajuste exportador geradores de recursos excedentes transferidos ao exterior, o que levou à relativa decadência brasileira.



Fonte: OIT (2013).

Gráfico 2 - Variação média anual do total das ocupações de trabalhadores (em \%).

A regressão econômica e social ganhou evidência ante as altas taxas de inflação, a desorganização das finanças públicas, a semiestagnação da renda por habitante, o elevado desemprego, a pobreza e a desigualdade social. A partir daí, o Brasil se distanciou do mundo desenvolvido, perdendo oportunidades de incorporar os avanços que decorreram, por exemplo, da revolução informacional. $^{4}$ 
Além disso, as políticas neoliberais adotadas na década de 1990 levaram ao precoce movimento da desindustrialização simultâneo à maior internacionalização do parque produtivo e ao fortalecimento dos setores primário exportador e financeiro. $\mathrm{O}$ desgaste do neoliberalismo tornou-se ainda mais insuportável com a grande crise internacional de 2008, que apontou, mais uma vez, os seus limites para o desenvolvimento do trabalho.

Um pouco antes disso, a vitória democrática de uma nova maioria política não liberal (no sentido econômico) constituída no interior do processo eleitoral de 2002 apontou para a possibilidade de um novo reposicionamento do país em relação ao mundo. A trajetória de expansão das ocupações no mundo e no Brasil permite identificar dinâmica distinta a partir do início do século XXI.

Ademais, considera-se também que a evolução da renda per capita ao ritmo médio de 2,5\% ao ano desde o início da década de 2000 aponta também para sinais de uma grande mudança em gestação no trabalho no Brasil. Certamente, o estabelecimento de uma nova maioria política antiliberal desde 2003 reforçado pelo caminho democrático e popular possibilitou a recuperação de vários segmentos sociais desestruturados pela regressão econômica e social das décadas de 1980 e 1990.

A recuperação do ritmo de crescimento econômico se deu paralelamente ao reforço do papel do Estado, sobretudo no âmbito do fundo social. A ampliação do gasto social em relação ao PIB potencializou a expansão da renda e do emprego, colocando em novas bases o enfrentamento de mazelas históricas acumuladas, como a pobreza e a concentração de renda.
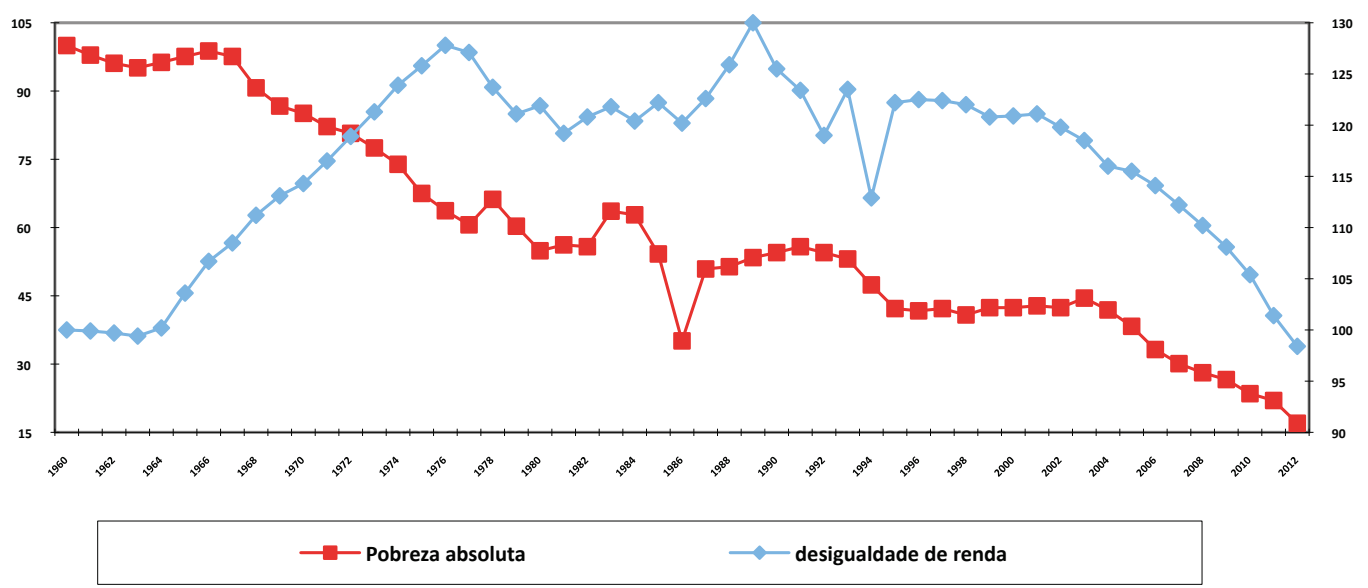

Fonte: IBGE (elaboração própria).

Gráfico 3 - Brasil: evolução dos índices de desigualdade pessoal da renda (Gini) e da taxa de pobreza entre 1960 e $2012(1960=100)$.

Para isso foi necessário reduzir parcela importante dos ganhos do rentismo financeiro. No ano 2013, por exemplo, o Estado transferiu aos rentistas 5,7\% do 
Produto Interno Bruto na forma de pagamento de despesas financeiras, enquanto em 2002 foram $14,2 \%$ do PIB.

Essa mudança no papel do Estado se traduziu não apenas na retomada dos investimentos públicos em infraestrutura, paralisada por mais de duas décadas, como no comportamento da pobreza e da desigualdade pessoal da renda. Três movimentos distintos podem ser percebidos em relação a isso nos últimos cinquenta anos.

O primeiro verificado nas décadas de 1960 e 1970 combinou elevado crescimento da desigualdade de renda com queda na taxa de pobreza. Para o aumento acumulado de $21,9 \%$ ( $1 \%$ ao ano, em média) no índice de desigualdade de renda (Gini), a taxa nacional de pobreza caiu $45,1 \%$ ( $1,9 \%$ ao ano, em média).

O segundo movimento manteve estabilizado relativamente o grau de desigualdade e a taxa de pobreza no Brasil. No período entre 1981 e 2003, por exemplo, a desigualdade caiu $2,8 \%(0,1 \%$ ao ano, em média), ao passo que a taxa de pobreza reduziu-se $19,8 \%(0,8 \%$ ao ano $)$.

Por fim, o terceiro movimento convergiu na queda tanto da taxa de pobreza como da desigualdade na renda. Dos anos 2003 a 2012, por exemplo, o índice de Gini reduziu-se 17,8\% (1,8\% ao ano, em média), enquanto a taxa de pobreza diminuiu $61,8 \%$ ( $5,5 \%$ ao ano, em média).

Em síntese, o retorno do crescimento econômico combinado ao conjunto de políticas públicas de renda (salário mínimo, programas de transferência de renda, entre outros) produziu trajetória inédita de inclusão social no Brasil.

Quadro l - Brasil - evolução da População Economicamente Ativa, da condição da ocupação e do desemprego entre 1940 e 2010 (variação média anual)

\begin{tabular}{l|c|c|c}
\hline \multicolumn{1}{c|}{ Itens } & $1940-1980$ & $1980-2000$ & $2000-2010$ \\
\hline PEA & $2,6 \%$ & $2,9 \%$ & $1,7 \%$ \\
\hline PEA ocupada & $2,6 \%$ & $2,2 \%$ & $2,5 \%$ \\
\hline Empregador & $3,3 \%$ & $1,6 \%$ & $-0,7 \%$ \\
\hline Conta própria & $1,8 \%$ & $2,1 \%$ & $2,4 \%$ \\
\hline Sem remuneração & $0,6 \%$ & $0,9 \%$ & $-5,4 \%$ \\
\hline Empregado & $3,6 \%$ & $2,4 \%$ & $3,4 \%$ \\
\hline - Com registro & $6,2 \%$ & $1,3 \%$ & $4,7 \%$ \\
\hline - Sem registro & $0,6 \%$ & $5,1 \%$ & $0,9 \%$ \\
\hline Desempregado & $0,5 \%$ & $11,9 \%$ & $-3,2 \%$ \\
\hline Taxa de informalidade* & $1,1 \%$ & $3,0 \%$ & $0,6 \%$ \\
\hline Taxa de precariação** & $1,1 \%$ & $3,7 \%$ & $-1,1 \%$ \\
\hline
\end{tabular}

* Soma dos ocupados por conta própria, sem remuneração e empregado sem registro.

** Soma de conta própria, sem remuneração e desempregado.

Fonte: IBGE - Censo demográfico - e MTE. 
Tal como a saída da Depressão de 1929, que representou a superação das políticas liberais até então dominantes, ${ }^{5}$ a retomada pós-crise de 2008 parece indicar para o Brasil um caminho próprio. ${ }^{6}$ Além disso, os resultados colhidos pelos governos pós-neoliberais desde 2002 reforçam a interpretação acerca de uma segunda grande transformação no trabalho, cujos avanços econômicos acoplados ao desenvolvimento social e trabalhista expressam-se pela redução do desemprego e da informalidade, bem como da pobreza e da desigualdade de renda.

A primeira década do século XXI apresenta resultados superiores aos verificados desde os anos 1940, quando da introdução dos direitos sociais e trabalhistas no Brasil. Destacam-se, por exemplo, a situação da precarização do trabalho e a presença da informalidade, bem como a queda do desemprego.

\section{Elementos fundantes para a consolidação da segunda grande transformação no trabalbo}

No âmbito da transição para sociedade de serviços ainda em construção, o conhecimento tende a se tornar um dos principais ativos da propulsão do desenvolvimento, cujo avanço da produtividade pertence ao comando do processo de desmaterialização das economias. Sob essas novas condições depositam-se as possibilidades adicionais da maior libertação do homem do trabalho pela sobrevivência (trabalho heterônomo), por meio da postergação do ingresso no mercado de trabalho para depois do cumprimento do ensino superior e da oferta educacional ao longo da vida.

Nesse sentido residem os elementos fundantes da consolidação da segunda grande transformação do trabalho no Brasil. Inicialmente, isso pode ser considerado pelo esvaziamento do peso relativo da economia nacional proveniente dos setores primário (agropecuária) e secundário (indústria e construção civil) ante a expansão do setor terciário (serviços e comércio).

Entre 1950 e 1980, por exemplo, o setor secundário aumentou sua posição relativa em $88,3 \%$, pois passou de $20,5 \%$ para $38,6 \%$ do PIB, enquanto o setor primário reduziu sua posição relativa em $63,6 \%$ (passou de $29,4 \%$ para $10,7 \%$ ). Nesse mesmo período, o setor terciário manteve praticamente inalterado o seu peso relativo.

Nos trinta anos seguintes, o setor primário perdeu $46, \%$ do seu peso relativo, ao passo que o setor secundário reduziu sua participação no PIB em 35,5\%. Somente o setor terciário cresceu $36,9 \%$, passando a representar em 2013 quase $70 \%$ de todo o Produto Interno Bruto brasileiro.

Aliado a isso, a sustentação do meio ambiente ganha importância com a necessidade de mudança do atual modelo de produção e consumo estimulado pelo processo de desmaterialização das economias modernas. Mas nem tudo, todavia, está definido. Há tendências que podem ser confirmadas à medida que os sujeitos históricos se apresentam capazes de construir seus próprios caminhos, orientados pela consolidação da liderança econômica, social e ambiental no atual cenário mundial pós-neoliberal em disputa. 


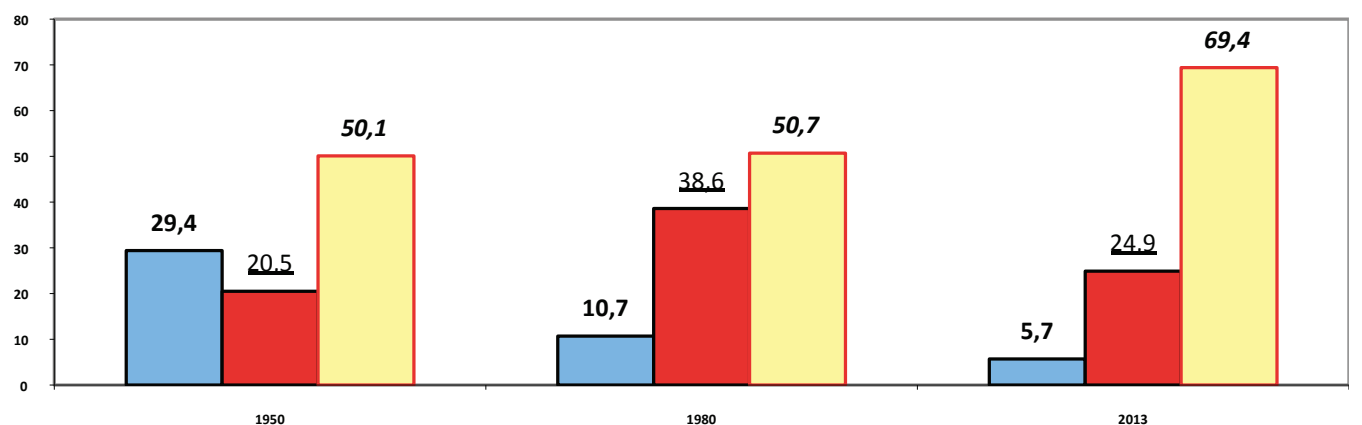

1980

2013

\begin{tabular}{|ll|}
\hline QPrimário & QSecundário \\
\hline
\end{tabular}

Fonte: IBGE/Contas nacionais (Elaboração própria).

Gráfico 4 - Brasil - evolução da composição do Produto Interno Bruto (em \%).

Este parece ser o espaço para a fundamentação da segunda grande transformação do trabalho no Brasil. Três aspectos são tratados a seguir, concernentes com o estado de saúde do conjunto da população, a dimensão do conhecimento e a perspectiva do trabalho humano.

No que concerne ao estado da educação destaca-se o reconhecimento $a$ priori acerca da atual modificação demográfica, com redução da parcela mais jovem e elevação do segmento etário mais velho. Ao mesmo tempo, percebe-se o aumento na expectativa média de vida, o que recoloca um conjunto de novas questões para as políticas de saúde, mobilidade, integração social, entre outras.

Cada vez mais se apresenta como possibilidade a expectativa de vida em torno dos cem anos de idade, ante os atuais 73 anos. Ademais da importante queda na taxa de mortalidade infantil, assiste-se à aceleração da redução na taxa de fecundidade feminina e do número de membros por domicílios. Diante disso ganham maior importância as novas estruturas familiares, muitas delas cada vez mais monoparentais, com crescente dificuldade de reprodução da tradicional sociabilidade domiciliar.

Acresce também ressaltar o estado de saúde da população, aquela expressa pela nova composição das causas de mortes entre os brasileiros. As doenças transmissíveis e por causas associadas a condições nutricionais, maternas e perinatais perdem importância, ao passo que aumentam as causas associadas às doenças não transmissíveis (cardiovasculares, psiquiátricas e neoplasias) e às causas externas (acidente de trânsito e violência).

Embora os recursos públicos e privados aumentem consideravelmente, o quadro de insegurança permanece sem diminuição. Em geral, o crime de violência atinge muito mais os jovens, especialmente os de sexo masculino e pertencentes a famílias de baixa renda. O Brasil se encontra entre os países de maiores taxas de homicídios de jovens no mundo (51,6 por 100 mil habitantes), segundo a Organização Mundial de Saúde (OMS). 
No mesmo sentido, a carência da infraestrutura nas cidades brasileiras associa-se às precárias condições de nossa mobilidade urbana, dos meios de transportes coletivos e individuais, não sendo desprezíveis as mortes ocasionadas por acidentes de trânsito. Assim, o estado de saúde da população requer, cada vez mais, políticas intersetoriais e articuladas que assistam o povo na sua totalidade.

Para a dimensão do conhecimento, não obstante avanços colhidos no processo educacional, sabe-se que há inegáveis descompassos e assimetrias ainda consideráveis em todo o território nacional. A começar pelo grau de analfabetismo populacional ainda persistente no início da segunda década do século XXI, com menos de $10 \%$ da população com quinze e mais anos de idade nessa circunstância.

Isso cresce de proporção se forem contabilizados os chamados analfabetos funcionais. Em geral, a concentração dos pobres e miseráveis, assim como a maior taxa de desemprego e ocupações precárias, assenta-se na população de menor escolaridade.

Em pleno curso da transição para a sociedade de serviços, a inserção no mercado de trabalho precisa ser gradualmente postergada, possivelmente para o ingresso na atividade laboral somente após a conclusão do Ensino Superior, com idade acima dos 22 anos, e saída sincronizada do mercado de trabalho para o avanço da inatividade. Tudo isso acompanhado por jornada de trabalho reduzida, o que permite observar que o trabalho heterônomo deva corresponder a não mais do que $25 \%$ do tempo da vida humana.

Nesse sentido que se apresenta a perspectiva do trabalho humano. Destaca-se que na antiga sociedade agrária, o começo do trabalho ocorria a partir dos cinco a seis anos de idade para se prolongar até praticamente a morte, com jornadas de trabalho extremamente longas (quatorze a dezesseis horas por dia) e sem períodos de descanso, como férias e inatividade remunerada (aposentadorias e pensões). Para alguém que conseguisse chegar aos quarenta anos de idade, tendo iniciado o trabalho aos seis anos, por exemplo, o tempo comprometido somente com as atividades laborais absorvia cerca de $70 \%$ de toda a sua vida.

$\mathrm{Na}$ sociedade industrial, o ingresso no mercado laboral foi postergado para os dezesseis anos de idade, garantindo aos ocupados, a partir daí, o acesso a descanso semanal, férias, pensões e aposentadorias provenientes da regulação pública do trabalho. Com isso, alguém que ingressasse no mercado de trabalho depois dos quinze anos de idade e permanecesse ativo por mais cinquenta anos teria, possivelmente, mais alguns anos de inatividade remunerada (aposentadoria e pensão).

Assim, cerca de $50 \%$ do tempo de toda a vida estariam comprometidos com o exercício do trabalho heterônomo. A parte restante do ciclo da vida, não comprometida pelo trabalho e pela sobrevivência, deveria estar associada à reconstrução da sociabilidade, estudo e formação, cada vez mais exigidos pela nova organização da produção e distribuição internacionalizada. 
Isso porque, diante dos elevados e constantes ganhos de produtividade, torna-se possível a redução do tempo semanal de trabalho de algo ao redor das quarenta horas para não mais que vinte horas. De certa forma, a transição entre as sociedades urbano-industrial e pós-industrial tende a não mais separar nítida e rigidamente o tempo do trabalho do não trabalho, podendo gerar maior mescla entre os dois, com maior intensidade e risco da longevidade ampliada da jornada laboral para além do tradicional local de exercício efetivo do trabalho.

Diante disso, constata-se que o melhor entendimento acerca do novo mundo do trabalho possibilita a reinvenção da pauta sindical comprometida com a construção de uma sociedade superior. Não pode haver dúvidas de que o novo desenvolvimento pressupõe papel ainda maior à educação.

O sistema educacional tal como existe atualmente se apresenta relativamente recente, embora com sinais de insuficiência. Até a transição da antiga sociedade agrária para a urbana e industrial, a educação era algo inexistente para as grandes massas da população. Tão somente as famílias aristocráticas possuíam condições de contratar tutores para filhos, enquanto a Igreja é que tratava de transferir o conhecimento formalizado ao longo dos anos.

No mundo agrário, o conhecimento comunitário era transmitido na velha forma "de pai para filho", em que os mais idosos possuíam importância relativa superior em razão do acúmulo das experiências vividas. De maneira geral, somente a passagem para a sociedade urbana e industrial altera o papel da educação, a partir da construção e difusão das escolas formais. Antes disso, a questão nacional, constituída pelo aparecimento dos Estados nacionais a partir do século XIX, tornou-se fundamental para a generalização da condição de povo associado aos limites da soberania de uma nação. Assim, a unificação da língua pátria e a identificação dos valores nacionais se mostraram fundamentais para a formação do conteúdo da educação formal.

Ademais, a emergência do trabalho na manufatura passou a exigir valores como disciplina e responsabilidade fabril, bem como operações básicas e linguagem comum, não mais transmitidas pelas famílias que viviam em comunidades na sociedade agrária. Nas cidades, as famílias não somente diminuíram de tamanho, como o trabalho passou a ser realizado pelos pais e distante do local de moradia.

A crise de sociabilidade no interior das famílias pertencentes à sociedade urbana e industrial terminou sendo enfrentada pela ação das políticas públicas. Com a difusão dos sistemas educacionais pelo Estado, o segmento etário de até quatorze anos foi libertado do trabalho, conforme ocorria na sociedade agrária, passando a inatividade necessária para cumprir o conteúdo do ensino como elemento fundante para o ingresso no mercado de trabalho.

Uma vez coberta a fase infantil de estudo, a passagem para o mercado de trabalho afastava dos bancos escolares. Assim, a educação do século XX se apresentou funcional aos requisitos de conformação dos Estados nacionais e de transição da inatividade ao mundo do trabalho. 
Com a terceira revolução tecnológica, que tem a emergência das novas tecnologias de comunicação e informação, as exigências educacionais ampliam-se rapidamente. Não parecem caber mais sistemas educacionais voltados apenas às fases etárias precoces.

Ademais de tornar o Ensino Superior o piso da nova sociedade do conhecimento, urge a instalação do sistema de educação para toda a vida. Se o conhecimento assume cada vez mais a condição de principal ativo gerador de riqueza, qual o sentido de se estudar pouco e em condições desfavoráveis?

Dentro desse contexto que se recoloca a temática do trabalho humano. Em geral, o funcionamento do mercado de trabalho relaciona ao longo do tempo uma variedade de formas típicas e atípicas de uso e remuneração da mão de obra com excedente de força de trabalho derivado dos movimentos migratórios internos e externos sem controles.

A ausência das reformas clássicas do capitalismo contemporâneo, como a agrária, possibilitou a transferência de grande parcela do excedente rural dos trabalhadores para as cidades. Também sem planejamento, as cidades absorveram grandes contingentes de trabalhadores alocados em formas marginais de ocupação, cuja informalidade inviabilizou o trabalho decente. Os escassos experimentos de democracia nas relações de trabalho comprometeram o potencial de atuação dos sindicatos nas formas de contratação coletiva mais próximas dos ganhos de produtividade alcançados nos setores econômicos.

Certamente o avanço econômico portador de forte expansão do emprego com elevação do valor real do salário mínimo e maior importância e efetividade das negociações coletivas de trabalho abriu uma nova fase na participação dos salários na renda nacional dos países da região. Ao mesmo tempo o salto nas políticas sociais, com aquelas associadas à garantia de renda aos segmentos mais pauperizados, permitiu retirar do mercado de trabalho crianças e adolescentes submetidos ao trabalho infantil, bem como às condições ainda existentes de trabalho escravo.

O resultado foi o avanço inegável da formalização da mão de obra. A queda no conjunto dos trabalhadores à margem do sistema de proteção social e trabalhista na década de 2000 foi evidente, mas há ainda muito que avançar.

Em grande medida, a heterogeneidade ocupacional deriva de taxas muito diferenciadas em termos do assalariamento e postos de trabalho associados aos setores econômicos de baixa produtividade. No Brasil, por exemplo, pelo menos a metade dos trabalhadores por conta própria pertence ao setor rural da economia.

No caso do desemprego da mão de obra, relativamente menor após dez anos de expansão econômica com distribuição de renda, segue, contudo, a desigualdade de sua maior expressão entre os jovens nos países da região. Em geral, o desemprego é mais alto também entre as mulheres, enquanto para os jovens, a taxa de desemprego tende a ser duas vezes maior que a registrada entre os adultos. 


\section{Considerações finais}

O sentido geral das mudanças registradas desde a primeira década do século XXI aponta para o desencadeamento de uma segunda grande transformação do trabalho no Brasil. A conjugação do regime democrático com a maior ampliação da renda por habitante foi acompanhada da redução da pobreza e da desigualdade de renda.

A marcha da valorização do trabalho ocorre pela queda do desemprego associada à elevação do emprego assalariado formal. Concomitantemente ao aumento real do salário mínimo registra-se o crescimento dos salários acima da inflação, o que expressa o vigor da retomada dos sindicatos em incorporar ganhos de produtividade gerados pela economia.

Mas para que o curso da grande transformação do trabalho não reproduza os equívocos observados entre as décadas de 1930 e 1970, a questão social exige um tratamento inovador em direção à maior eficiência e eficácia das políticas sociais e laborais. Isto é, a redefinição do Estado por ações cada vez mais matriciais e articuladas no interior do conjunto das políticas de proteção (previdência, assistência e saúde), promoção (educação, cultura e trabalho) e infraestrutura (habitação, urbanismo e saneamento) social.

De um lado, haveria a possibilidade de melhora no enfrentamento da heterogeneidade ainda existente no país; e, de outro, a centralidade da agenda política nos novos vetores da riqueza, ou seja, a reindustrialização do parque produtivo com ênfase nos setores de serviços produtivos.

Assim, a consolidação da segunda transformação do trabalho implicaria o estabelecimento de uma nova regulação, especialmente aquela associada ao desenvolvimento do trabalho imaterial. O caminho próprio para o novo salto civilizatório seguiria em frente.

\section{Notas}

1 Mais referências em Agarwala e Singh (2010).

2 Mais detalhes em Cano (1999a) e Tavares (1981).

3 Ver em Faletto (2009) e Kowarick (1975).

4 Maiores detalhes em Cano (1999b) e Bacha e Mendoza (1987).

5 Sobre o liberalismo, ver Morais (1997) e Keynes (1986).

6 Sobre o pós-neoliberalismo, ver Sader e Gentile (2007).

\section{Referências}

AGLETTÁ. M. Regulation et crises du capitalisme. Paris: Calmann-Lévy, 1976.

AGARWALA, A.; SINGH, S. A economia do subdesenvolvimento. Rio de Janeiro: Contraponto; CICF, 2010.

AMSDEN, A. A ascensão do "resto". São Paulo: Editora Unesp, 2004. 
ARRIGHI, G. A ilusão do desenvolvimento. Petrópolis: Vozes, 1997.

BACHA, E.; MENDONZA, M. Recessão on crescimento: FMI e Banco Mundial na América Latina. Rio de Janeiro: Paz e Terra, 1987.

BÉRTOLA, L.; OCAMPO, J. Desenvolvimento, vicissitudes e desigualdade. Madrid: SGIB, 2010.

BOMFIM, M. América Latina: males de origem. Rio de Janeiro: CEPS, 2008,

CANO. W. América Latina: do desenvolvimentismo ao neoliberalismo. In: FIORI, J.

(Org.) Estados e moedas no desenvolvimento das nações. Petrópolis: Vozes, 1999a.

Unesp, 1999b.

Soberania e politica econômica na América Latina. Campinas: Unicamp;

CARNEIRO, R. Commodities, choques externos e crescimento: reflexões sobre a América

Latina. Série macroeconomia del desarrolllo, 117. Santiago, 2012.

CEPAL. Da inovação à política pública. Santiago, 2011.

. La hora de la igualdad. Santiago, 2012.

DOSMAN, E. Raúl Prebisch: a construção da América Latina e do Terceiro Mundo. Rio de Janeiro: Contraponto; CICF, 2011.

FALETTO, E. Dimensiones sociales, politicas y culturales del desarrollo. Santiago: Flacso, 2009.

FIORI, J. Estados e moedas no desenvolvimento das nações. Petrópolis: Vozes, 1999.

FIORI, J.; MEDEIROS, C. Polarização e crescimento. Petrópolis: Vozes, 2001.

FRIEDEN, J. Capitalismo global. Barcelona: M. Crítica, 2007.

FRIEDMAN, B. As consequências morais do crescimento econômico. Rio de Janeiro: Record, 2009.

KEYNES, J. O fim do "laissez faire”. In: SZMRECSÁNYI, T. (Org.) Keynes. São Paulo: Ática, 1986. p.106-26.

KOWARICK, L. Capitalismo e marginalidade na América Latina. São Paulo: Paz e Terra, 1975.

LOVE, J. A construção do terceiro mundo. Rio de Janeiro: Paz e Terra, 1998.

MADDISON, A. Perspectives on Global Economic Progress and Human Development. Annual Symposium, 2008.

MELO, J. Capitalismo tardio. São Paulo: Brasiliense, 1981.

MORAIS, R. Liberalismo e neoliberalismo. Primeira versão, 73. Campinas: IFCH/Unicamp, 1997.

OCDE. Perspectives du développement mondial. Paris: OCDE, 2012.

Global Employment Trends. Gèneve: OCDE, 2013.

OLIVEIRA, C. Processo de industrialização: do capitalismo original ao atrasado. São Paulo: Editora Unesp, 2002.

PALMA, G. Gansos voadores e patos vulneráveis. In: FIORI, J. (Org.) O poder americano. Rio de Janeiro: Vozes, 2004. 
PINTO, A. Naturaleza e implicaciones de la "heterogeneidad estructural" de La América Latina. México: FCE, 1970.

POCHMANN, M. Desenvolvimento e perspectivas novas para o Brasil. São Paulo: Cortez, 2010.

. O trabalho no Brasil pós-neoliberal. Brasília: Liber, 2011.

. Subdesenvolvimento e trabalho. São Paulo: LTr., 2013.

- A vez dos intocáveis no Brasil. São Paulo: FPA, 2014.

PRADO, A. Neoliberalismo e desenvolvimento: a desconexão trágica. Campinas: IE/ Unicamp, 2006.

OIT Global Employment Trends. Gèneve, 2013.

ROUDART, L.; MAZOYER, M. Histórias das agriculturas no mundo. São Paulo: Editora Unesp, 2009.

SADER, E.; GENTILE, P. Pós-neoliberalismo: as políticas sociais e o Estado democrático. 7.ed. Rio de Janeiro: Paz e Terra, 2007.

SANTOS, T. O desenvolvimento latino-americano: passado, presente e futuro. Niterói: UFF, 2010.

TAVARES, M. Problemas de industrialización avanzada em capitalismos tardios. México: Revista Cide, 1981.

VERGOPOULOS, K. Globalização: o fim de um ciclo. Rio de Janeiro: Contraponto, 2005.

RESUMO - O presente artigo discute a hipótese de o Brasil estar diante de uma segunda grande transformação do trabalho neste início do século XXI. Como grande transformação, compreende-se o curso da atual estruturação do mercado de trabalho explicitado pela expansão do assalariamento formal e a queda do desemprego, desigualdade de renda e pobreza. Tal movimento diferencia-se da primeira grande transformação do trabalho observada durante as décadas de 1930 a 1980, quando o país perseguiu importante fase de consolidação da sociedade urbana e industrial. Por ser interrompido nas duas últimas décadas do século passado pela regressão econômica e social, o Brasil somente passou a sinalizar uma segunda transformação do trabalho em novas bases mediante o fortalecimento do setor de serviços que aguarda, ainda, o reposicionamento do Estado em termos de novas políticas públicas.

PALAVRAS-CHAVE: Trabalho, Emprego, Salário, Economia.

ABSTRACT - This article discusses the hypothesis that Brazil is facing a second great transformation of labor in the early 21 st century. Great transformation is understood as the current structure of the labor market, with an increasing number of formal wage earners and falling unemployment, income inequality and poverty. This movement differs from the first major transformation of labor (1930s to 1980s), when the country pursued an important consolidation of urban and industrial society. Having been stopped in the 
tracks in the last two decades of the 20th century by economic and social regression, Brazil only now begins to give signs of a second transformation of labor, established in new foundations, through the strengthening of the service sector - which, incidentally, still awaits the State to reposition itself in terms of public policies.

KEYWORDS: Labor, Employment, Salary, Economy.

Marcio Pochmann é professor do Instituto de Economia e pesquisador do Centro de Estudos Sindicais e de Economia do Trabalho da Universidade Estadual de Campinas. @ - marciopochmann@yahoo.com.br

Recebido em 30.6.2014 e aceito em 2.7.2014.

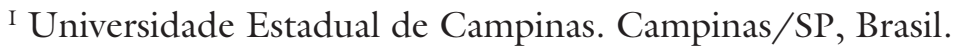

